\title{
Inclusão no Ensino Superior: políticas e práticas na Universidade Federal da Grande Dourados
}

\author{
Washington Cesar Shoiti Nozu \\ Universidade Federal da Grande Dourados - Dourados - MS - Brasil \\ Marilda Moraes Garcia Bruno \\ Universidade Federal da Grande Dourados - Dourados - MS - Brasil \\ Leonardo Santos Amâncio Cabral \\ Universidade Federal de São Carlos - São Carlos - SP - Brasil
}

\section{Resumo}

Considerando os desdobramentos da proposta de inclusão no âmbito do Ensino Superior, este trabalho objetiva investigar as ações da Universidade Federal da Grande Dourados (UFGD) voltadas, nos últimos 10 anos, aos acadêmicos tidos como Público-Alvo da Educação Especial (PAEE). Sob a abordagem do estudo de caso exploratório, de caráter descritivo, os dados da pesquisa evidenciam políticas, práticas organizacionais e estratégias, aqui apresentadas e discutidas em três eixos temáticos: a) Ações de Ensino, Pesquisa e Extensão; b) Serviços ofertados ao PAEE; c) Inclusão na UFGD: desafios e perspectivas. Os resultados alcançados reforçam, no microcontexto investigado, a necessidade contínua de uma responsabilidade compartilhada, coletiva e colaborativa, no sentido de desalojar as mais diversas barreiras que se interpõem, quotidianamente, no percurso de estudantes universitários com necessidades educacionais específicas.

Palavras-chave: Educação inclusiva; ensino superior; educação especial.

\section{Inclusion in Higher Education:}

\section{policies and practices at the Federal University of Grande Dourados}

\begin{abstract}
Considering the implications of the proposal for inclusion in Higher Education, this work aims to investigate the actions of the Federal University of Grande Dourados (UFGD), which have been focused in the last 10 years on the Academic Special Education Target (PAEE). Under the descriptive exploratory case study approach, the research data show policies, organizational practices and strategies, presented and discussed here in three thematic axes: a) Teaching, Research and Extension Actions; b) Services offered to PAEE; c) Inclusion in the UFGD: challenges and perspectives. The results achieved reinforce, in the microcontext investigated, the continuing need for a shared, collective and collaborative responsibility, in order to dislodge the most diverse barriers that are interposed, daily, in the course of university students with specific educational needs.
\end{abstract}

Keywords: Inclusive education; higher education; special education.

\section{Inclusión en la enseñanza superior:}

\section{políticas y prácticas en la universidad federal de la Gran Dourados}

\begin{abstract}
Resumen
Considerando los desdoblamientos de la propuesta de inclusión en el ámbito de la Enseñanza Superior, en este estudio se tiene el objetivo de investigar las acciones de la Universidad Federal de la Gran Dourados (UFGD) volcadas, en los últimos 10 años, a los académicos considerados como Público-Objetivo de la Educación Especial (PAEE). Bajo el abordaje del estudio de caso exploratorio, de carácter descriptivo, los datos de la investigación evidencian políticas, prácticas organizacionales y estrategias, aquí presentadas y discutidas en tres ejes temáticos: a) Acciones de Enseñanza, Pesquisa y Extensión; b) Servicios ofrecidos al PAEE; c) Inclusión en la UFGD: desafíos y perspectivas. Los resultados alcanzados refuerzan, en el micro-contexto investigado, la necesidad continua de una responsabilidad compartida, colectiva y colaborativa, en el sentido de desalojar las más diversos obstáculos que se interponen, cotidianamente, en el recorrido de estudiantes universitarios con necesidades educacionales específicas.
\end{abstract}

Palabras clave: Educación inclusiva; enseñanza superior; educación especial. 


\section{Introdução}

A perspectiva inclusiva atual tem se apresentado, de modo polissêmico, como elemento legítimo e recorrente na agenda das políticas públicas contemporâneas, articulando-se, principalmente, aos corolários dos direitos humanos e da democracia, num complexo jogo de influências globais-locais, ideológicas, econômicas, sociais e culturais que incide diretamente na democratização do acesso a todos os níveis de ensino do sistema educacional brasileiro.

No que tange ao Ensino Superior, especificamente, esse movimento intensificou-se em diversos países a partir da década de 1960, sobretudo quando suas instituições viram sua identidade sendo abalada pelo atrofiamento de sua dimensão cultural e sua concomitante expansão, popularização e reconfiguração de suas funções diante às novas exigências sociais e econômicas, criando pontos de tensão "tanto no relacionamento das universidades com o Estado e a sociedade como no interior das próprias universidades enquanto instituições e organizações" (Santos, 1997, p. 189).

No Brasil, ainda que tenha sido instaurada a reforma universitária por meio da Lei $n^{\circ} 5.540 / 1968$, perduravam mecanismos excludentes de acesso a esse nível de ensino, com barreiras seletivas ritualizadas, sobretudo quando consideradas as condições socioeconômicas e oportunidades de escolarização de seus candidatos, somadas a fatores como raça, etnia, deficiência, gênero, dentre outros (Peixoto, 2001).

É nesse cenário que nos voltamos especificamente às questões inerentes à escolarização e formação profissional dos alunos considerados como Público-Alvo da Educação Especial (PAEE)1. Isso porque, ainda que a "Declaração dos Direitos das Pessoas Deficientes"2, publicada na década de 1970, tivesse recomendado aos países membros da Organização das Nações Unidas (ONU) que garantissem ao PAEE os mesmos direitos fundamentais que seus concidadãos, no Brasil isso se deu de maneira incipiente, sobretudo no âmbito do Ensino Superior (Bruno,2011; Cabral, Mendes, De Anna, \& Ebersold, 2015).

Nos anos de 1980, os princípios promulgados pela ONU para o Ano Internacional da Pessoa com Deficiência, instituído em 1981, e para a Década das Nações Unidas para a Pessoa com Deficiência - 1983 a 1992, contribuíram com o respaldo ao reconhecimento do direito de acesso dessa população a todos os níveis de ensino. Nessa conjuntura política e histórica, a Constituição Federal de 1988 passa a preconizar a implantação de políticas públicas sociais de caráter universal sob a disseminação de um discurso de "inclusão social" (Cury, Horta, \& Fávero, 1996).

\footnotetext{
1 Alunos com deficiência, transtornos globais do desenvolvimento e altas habilidades/superdotação.

2 Promulgada pela Organização das Nações Unidas em 1975, contribui para uma década em que as decisões legislativas relacionadas às pessoas com deficiência avançaram em diversos países no sentido de efetivar, de diferentes modos, suas políticas de mainstreaming, intégration, integrazione ou de integração, assim como foi adotada no Brasil.
}

Ao longo dos anos de 1990, os Planos Plurianuais (PPAs) e os Planos Nacionais de Educação (PNEs) são rediscutidos e as modalidades de ingresso ao Ensino Superior passam a ser colocadas em questão, tendo em vista tanto o aumento do número de conclusões no Ensino Médio, quanto os mecanismos seletivos subsequentes a percursos escolares deficitários no âmbito da Educação Básica. Esse movimento dialogaria com os preceitos da "Declaração Mundial Sobre Educação Superior no Século XXI: visão e ação" (Unesco, 1998) e, naquele contexto, algumas iniciativas voltadas especificamente à promoção do acesso e permanência de estudantes PAEE no Ensino Superior eram já identificadas em instituições como:Universidade Federal do Paraná, em 1991; Universidade Estadual do Oeste do Paraná e Universidade Estadual de Campinas, em 1992; Universidade Federal do Rio de Janeiro, em 1993; e Universidade de São Paulo, em 1994 (Cabral, 2017).

Na década seguinte, a necessidade da ampliação de vagas no Ensino Superior brasileiro, inclusive ao PAEE, é salientada pelo Plano Nacional de Educação 2001-2010, sendo essa uma perspectiva transversal aos subsequentes PPAs instaurados no Brasil. Em níveis institucionais, ao longo daqueles anos, algumas provisões ao PAEE se reforçaram e voltaram-se não somente ao acesso, mas ao apoio e acompanhamento dessa população, com a finalidade de prover sua permanência e sucesso acadêmico ${ }^{3}$, indo ao encontro das palavras de Boaventura de Sousa Santos, que sugere:

Talvez seja mais correto designar a área do acesso como acesso/permanência ou mesmo acesso/permanência/ sucesso, uma vez que o que está em causa é garantir não só o acesso, mas também a permanência e o sucesso dos estudantes oriundos de classes ou grupos sociais discriminados (Santos, 2005, pp. 68-69).

À luz dessa perspectiva inclusiva, desde 2005 o "Programa Incluir" reconheceu a importância de se fomentar ações para a criação e a consolidação de núcleos de acessibilidade no âmbito das Instituições Federais de Ensino Superior (IFES). Vale ressaltar que, naquele mesmo ano, no bojo do Programa de Expansão das Instituições Federais de Ensino Superior no Brasil, implementado pelo governo federal, foram criadas 18 novas universidades federais em um processo de democratização do acesso ao Ensino Superior. É nesse movimento, então, que surge no Centro-Oeste brasileiro a Universidade Federal da Grande Dourados (UFGD), objeto da investigação ora apresentada.

Diante desse breve panorama e atento às relações políticas globais e locais, atreladas a marcos históricos e iniciativas concretas desenvolvidas nos mais diversos micro-

3 Na Universidade Federal do Paraná, em 2002, foi instituído o Programa de Acompanhamento ao Estudante com Necessidades Educacionais Especiais - PROENE; na Pontifícia Universidade Católica de Curitiba, em 2004, foi implementado o Grupo de Trabalho de Apoio aos Universitários com Necessidades Especiais - GT - AUNE; em 2006, na Universidade Federal de Santa Maria, iniciava-se um programa de atendimento a essa população. 
contextos universitários, o presente estudo tem a intenção de contribuir com a produção do conhecimento sobre os fatores que podem incidir sobre a promoção do acesso, permanência e sucesso do PAEE no Ensino Superior brasileiro. Mais especificamente, tem por escopo nodal investigar as ações da UFGD voltadas, nos últimos 10 anos, aos acadêmicos tidos como PAEE, vislumbrando um estrito diálogo com estudos nacionais e internacionais que discutem a temática da inclusão dessa população no Ensino Superior.

\section{Método}

Considerando-se os desafios inerentes à promoção do acesso, permanência e sucesso do PAEE enfrentados por diversas Instituições de Ensino Superior (IES) brasileiras, sobretudo ao longo da última década, a presente pesquisa foi realizada sob a abordagem de estudo de caso exploratório de caráter descritivo (Gil, 2009; Thacher, 2006; Yin, 2005).

O estudo foi desenvolvido no âmbito da UFGD, criada em 2005 a partir do desmembramento do Centro Universitário de Dourados (CEUD), campus da Universidade Federal de Mato Grosso do Sul (UFMS), na cidade de Dourados, tendo como meta principal atender à demanda de formação, em nível superior, no contexto do sul do Estado de Mato Grosso do Sul, considerando os aspectos fronteiriços com a República do Paraguai, bem como a presença da população indígena Guarani (Kaiowá/Ñandeva e Terena) e sua influência na construção da identidade sociocultural da região.

Atualmente, a instituição pesquisada oferta 39 cursos de graduação (34 presenciais e cinco à distância), além de dois cursos (Licenciatura Intercultural Indígena Teko Arandu e Licenciatura em Educação do Campo) no regime da Pedagogia de Alternância, organizados em dois tempos - tempo universidade e tempo comunidade. E, em nível de pós-graduação, oferece 20 cursos de especialização (15 presenciais e cinco à distância), três residências na área da saúde, 21 cursos de mestrado e nove cursos de doutorado.

É nesse cenário que esta pesquisa foi realizada, com a adoção criteriosa de procedimentos metodológicos realizados em quatro etapas, a saber:

$1^{a}$ etapa - levantamento bibliográfico e documental: exploração de referências que tratassem da temática no âmbito da comunidade científica e da produção políticonormativa nacional e internacional:

$2^{a}$ etapa - identificação e seleção de documentos institucionais: por meio de site institucional e acervo de setores da instituição explorada (Reitoria, Pró-Reitorias, Laboratórios e Núcleos);

$3^{a}$ etapa - sistematização, tratamento e análise dos dados.

$4^{a}$ etapa - apresentação dos dados e diálogo com a literatura.
Assim, corroborando o objetivo desta investigação, fazemos referência a Yin (2005) e a Thacher (2006), que ressaltam a importância do desenvolvimento de estudos de casos por reunir informações que contribuem com a apreensão de uma realidade, auxiliando a comunidade científica e acadêmica na possível resolução de problemas relacionados à temática.

Nesse sentido é que nos propusemos a explorar e a descrever historicamente as políticas, ações, os desafios e as perspectivas de inclusão do PAEE na UFGD na última década, tendo como marco temporal a implementação do Programa Incluir, em 2007, no âmbito da instituição pesquisada.

\section{Resultados}

O Estatuto da UFGD expressa em seus princípios e diretrizes a indissociabilidade entre ensino, pesquisa e extensão; a igualdade de condições para acesso e permanência na Universidade; a atenção às diferenças individuais dos estudantes e às peculiaridades regionais.

Assim, propõe-se uma Universidade inclusiva que busca ser concebida em sua dimensão sociocultural e política, em um processo de reflexão sobre o contexto intercultural à luz dos elementos que compõem o Plano de Desenvolvimento Institucional (PDI) da UFGD o qual, para sua construção, passa debates junto à comunidade acadêmica e aos órgãos gestores, com o intuito de possibilitar mudanças conceituais e políticas que possam expressar na transformação da cultura universitária.

Nessa perspectiva,a UFGD, ao longo dos últimos dez anos, tem se movimentado para a construção de políticas, práticas organizacionais e estratégias direcionadas à inclusão do PAEE. Tais atividades serão apresentadas nos seguintes eixos temáticos: a) Ações de Ensino, Pesquisa e Extensão; b) Serviços ofertados ao PAEE; c) Inclusão na UFGD: desafios e perspectivas.

\section{a) Ações de Ensino, Pesquisa e Extensão}

No presente eixo temático, ao longo dos últimos dez anos as ações respaldaram-se na disponibilização de três disciplinas relacionadas à temática da inclusão do PAEE no âmbito dos cursos de graduação e três em nível de pós-graduação, além da implementação de quatro cursos específicos da área; no desenvolvimento de dois projetos institucionais, na consolidação de três grupos de pesquisa e na defesa de quatro dissertações que abordavam a temática da inclusão do PAEE no Ensino Superior; além da promoção de três eventos e um curso de extensão.

-Ações de Ensino: a) institucionalização da disciplina Educação Especial como obrigatória em todos os cursos de licenciaturas da UFGD (2007); b) oferta das disciplinas de Libras e de Direitos Humanos, Cidadania e Diversidades em todos os cursos de licenciatura e bacharelado (2008); c) oferta das disciplinas Política de Inclusão e Tópicos de 
Educação Especial no Programa de Pós-Graduação em Educação (PPGEdu) (2008) e da disciplina Educação, Direitos Humanos e Inclusão no Programa de Pós-Graduação em Fronteiras e Direitos Humanos (PPGFDH) (2017); d) implementação do Polo Letras Librasna Faculdade de Educação (FAED) (2008-2011), em parceria com a Universidade Federal de Santa Catarina, com formação de professores Português-Libras e Bacharel Intérprete; e) criação do curso permanente de Letras Libras na Faculdade de Educação à Distância (EaD), por meio de adesão ao Programa Viver sem Limites, do governo federal (2013); f) criação do Curso de Especialização em Educação Especial (2017); g) formação na FAED do Pólo Pedagogia Bilíngue, ofertado pelo Instituto Nacional de Educação dos Surdos (INES) (com previsão para início em 2018).

- Ações de Pesquisa:1) Projetos de Pesquisas Institucionais: a) "Núcleo de Tecnologia Assistiva: promoção da aprendizagem, inclusão digital/social na UFGD" (20131015); b) "Identificando Perfis e Necessidades dos Estudantes Universitários com Deficiência para a Potencialização dos Serviços de Apoio e Orientação Acadêmica da UFGD" (2015-2017); 2) Grupos de Pesquisa: a) Grupo de Estudos e Pesquisa em Educação Inclusiva (GEPEI), criado em 2006; b) Grupo de Estudos e Pesquisas em Educação Especial (GEPES), criado em 2009; c) Grupo de Estudos e Pesquisas em Educação e Tecnologias da Informação e Comunicação (GEPETIC), criado em 2011; 3) Pós-Graduação: quatro dissertações defendidas sobre a temática, no âmbito do PPGEdu/UFGD 4 .

-Ações de Extensão: 1) Eventos: a) I Seminário de Inclusão no Ensino Superior: acesso e permanência (2008); b) Colóquios sobre Cultura Escolar e a Educação Inclusiva (2009-2010); c) I Workshop para Atuação em Contextos Educacionais Inclusivos de Mato Grosso do Sul: da Educação Básica ao Ensino Superior (2015); 2) Cursos: a) "Curso de Capacitação Profissional Atendimento Educacional Especializado: seu pensar, sentir e fazer" (2016 e 2017).

b) Serviços ofertados ao PAEE

Transversalmente às ações de ensino, pesquisa e extensão da UFGD, permearam as iniciativas concebidas, planejadas e executadas por dois setores institucionais, ao longo dos últimos 10 anos, a saber:

- Laboratório de Acessibilidade e Práticas Inclusivas $($ LAPEI) 5 (2007 a 2015), constituído na UFGD por meio de

4 a) "A Política de Acessibilidade na cidade de Dourados/MS: um estudo sobre as práticas discursivas e não discursivas", por Glaucimara Lopes Schneider Hova (2010); b) "O Intérprete de Língua de Sinais sob o Olhar do Aluno Surdo no Ensino Superior: uma análise do discurso na perspectiva foucaultiana", por Janete Nantes de Melo (2012); c) "Educação, Inclusão e Tecnologias da Informação e Comunicação: o uso de tecnologias da informação e comunicação como recurso para inclusão de deficientes auditivos em Dourados/MS", por Graziely Vilhalva Nascimento (2013); d) "O Impacto dos Recursos de Tecnologia Assistiva na Educação e Inclusão de Pessoas com Deficiência Visual", por Ricardo Augusto Lins do Nascimento (2015).

5 De 2007 a 2014, as principais atividades voltadas à acessibilidade e inclusão na UFGD foram realizadas por intermédio do LAPEI, sob a coordenação da Profa. Dra. Marilda Moraes Garcia Bruno (de 2007 recursos advindos de dois editais (2007 e 2009) do "Programa Incluir: Acessibilidade no Ensino Superior", da Secretaria de Educação Superior do Ministério da Educação. Ao longo de sete anos consecutivos, as ações do LAPEI vislumbraram o apoio no processo de organização da instituição como um todo, de maneira a garantir o acesso a permanência, a progressão e o sucesso acadêmico dos estudantes PAEE. Em meio a movimentos de reestruturação de nova gestão universitária, no ano de 2015, o LAPEI passa a ter suas atribuições mais adstritas ao âmbito da FAED da UFGD. Contudo, esse permaneceu como sendo um espaço de apoio e forlalecimento de uma cultura institucional inclusiva, passando a colaborar diretamente com o novo setor institucional que surgiria naquele ano, como órgão suplementar da reitoria para as questões inerentes à inclusão e acessibilidade do PAEE no âmbito da instituição.

- Núcleo Multidisciplinar para a Inclusão e Acessibilidade (NuMIAc) ${ }^{6}$ (de 2015 a atual), instituído visando a manutenção das propostas de acesso ede permanência dos alunos PAEE da UFGD. O NuMIAc é caracterizado como um serviço de orientação acadêmica e profissional a ser oferecido aos estudantes PAEE (Cabral, 2015). A proposta de composição da equipe multidisciplinar do NuMIAc, valendo-se da intersetorialidade institucional e de seu conselho diretor, passou a prever a participação de: a) docentes e técnicos com capacitação em Educação Especial e/ou em áreas relacionadas à inclusão e acessibilidade do PAEE; b) psicólogos; c) assistentes sociais; d) pedagogos; e) estagiários; f) representantes da sociedade civil (Ufgd, 2016).

\section{c) Inclusão na UFGD: desafios e perspectivas futuras}

Ao analisar as políticas e práticas institucionais realizadas ao longo dos últimos dez anos, seja no âmbito organizacional pautado no tripé do ensino, pesquisa e extensão, seja na esfera dos serviços ofertados, é possível identificar que, para cada ação inerente ao ingresso, permanência e sucesso acadêmico do PAEE, existiram e ainda persistem desafios que foram, que são e/ou que deverão ser enfrentados no quotidiano acadêmico, vislumbrando-se sempre perspectivas futuras para atuações concretas. Nesse sentido, a partir da sistematização e tratamento dos dados da presente pesquisa, foi possível elencarmos a nossa análise nos seguintes sub-eixos temáticos:

\section{- Adequações para o Ingresso no Ensino Superior}

a 2013) e das professoras Dra. Morgana de Fátima Agostini Martins e Dra ${ }^{a}$. Aline Maira da Silva (no ano de 2014).

6 Implementado pelo Prof. Dr. Leonardo Santos Amâncio Cabral, em 2015. Devido à sua redistribuição para a Universidade Federal de São Carlos - UFSCar, em janeiro de 2017, a Profa ${ }^{a}$. Dr ${ }^{a}$. Mirlene Ferreira Macedo Damázio foi nomeada como chefe do NuMIAc para assumir as iniciativas inerentes à inclusão dos estudantes PAEE na UFGD, dando, assim, continuidade às atividades já implementadas e possibilidade para novas proposições. 
Conforme o Aviso Circular $n^{\circ} 277 / 1996$ do Ministério da Educação, que prevê condições especiais de acesso aos candidatos que compõem o PAEE nos concursos vestibulares, 0 LAPEI atuou desde 2007, conjuntamente com o Centro de Seleção da UFGD, para adequações e promoção da acessibilidade a surdos, cegos e/ou indígenas, os quais se configuravam como possíveis candidatos nos processos seletivos para a graduação e em concursos para cargos da carreira do magistério e técnico-administrativos. Nessa perspectiva, entendemos que tais práticas representam "um mecanismo que atenua as dificuldades e observa as peculiaridades dos candidatos" por meio do atendimento de suas especificidades e da oferta de condições mais equitativas para o ingresso no Ensino Superior (Moreira, Bolsanello, \& Seger, 2011, p. 136).

Ainda assim, predominam nesse processo alguns desafios, como o reconhecimento das diferenças nos processos seletivos. Quando consideramos as especificidades dos candidatos surdos, por exemplo, é assegurado que a língua portuguesa seja adotada como segunda língua, garantindo-lhes a presença do intérprete. Contudo, esse sistema ainda pode configurar-se como insuficiente, quando considerado que os processos seletivos tradicionais são concebidos tendo como referência a Língua Portuguesa como primeira língua, denotando possíveis entraves não somente durante a realização da prova, como também no processo de avaliação, sobretudo no que se refere às provas discursivas. Como reflexo desse processo, os surdos tendem a optar por cursos que se aproximam de sua cultura e, no caso da UFGD, no período de 2012 a 2017, isso ocorreu no âmbito do curso de Letras Libras, o qual recebeu 41 dos 51 registros de matrículas de alunos com deficiência auditiva ou surdez na instituição.

Contudo, uma vez na instituição, independentemente do tipo de necessidades educacionais específicas, foram necessárias estratégias que propiciassem, para além do ingresso, condições de permanência e sucesso acadêmico aos estudantes PAEE.

\section{- Identificação, acolhimento e acompanhamento de estudantes PAEE}

A necessidade da identificação e avaliação das necessidades específicas dos estudantes PAEE ingressantes na instituição urgia, tanto daqueles que se autodeclaravam,
Tabela 1. Número de Alunos Atendidos pelo LAPEI (2008-2014).

\begin{tabular}{cc}
\hline Ano & Alunos atendidos \\
\hline 2008 & 20 \\
\hline 2009 & 22 \\
\hline 2010 & 22 \\
\hline 2011 & 26 \\
\hline 2012 & 28 \\
\hline 2013 & 12 \\
\hline 2014 & 06 \\
\hline
\end{tabular}

Fonte: relatórios internos do LAPEI.

quanto daqueles que eram identificados pelos docentes, coordenadores de curso e/oudiretores das faculdades. Nesse sentido, após ampla sensibilização do contexto universitário em relação à existência de um setor específico (que se dedicava em contribuir) responsável pelas questões da inclusão do PAEE no âmbito da instituição, os estudantes passaram a frequentar os serviços oferecidos, reconhecendo-os como apoio adicional ao seu percurso acadêmico, conforme indicado na Tabela 1.

Concomitante a esse processo, foram realizadas, em conjunto com os professores, iniciativas que visavam garantir meios de acesso ao currículo e de utilização de recursos e equipamentos de Tecnologia Assistiva, bem como da criação deestratégias para potencializar o processo de comunicação e aprendizagem dos alunos PAEE matriculados na UFGD.

Todavia, mesmo com o fomento de ações nessa direção, a identificação de estudantes PAEE na UFGD ainda tem se constituído num desafio significativo, tanto no que tange à aceitação e autodeclaração do próprio estudante sobre sua condição, quanto no que diz respeito à compreensão, por parte dos estudantes universitários como um todo, sobre o conceito de necessidades educacionais específicas e sobre sua possível elegibilidade ao PAEE. A Figura 1 apresenta o quantitativo de estudantes que, a partir de 2012, via sistema de matrículas da UFGD, se autodeclararam nesta condição.

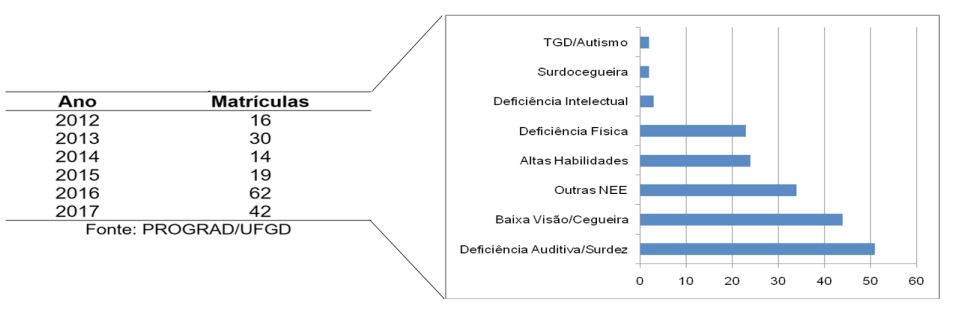

Figura 1. $\mathrm{N}^{\circ}$ de Matrículas de Estudantes Autodeclarados como PAEE na UFGD e sua frequência por NEE (2012-2017). Legenda: TGD - Transtornos Globais do Desenvolvimento; NEE - Necessidades Educacionais Especiais.

Fonte: elaboração própria a partir de dados da PROGRAD/UFGD. 
Os dados sugerem que, se por um lado, o acréscimo elevado de matrículas nos últimos dois anos podetrazer suspeitas sobre o sistema de autodeclaração, por outro, esse número pode estar aquém da realidade, uma vez que esse processo envolve a aceitação do estudante em relação à sua própria condição, perpassando por aspectos da esfera psicológica, interpessoal, intrapessoal, acadêmica, de aprendizagem, social, cultural, econômica e, também, biológica (Cabral \& cols., 2015).

\section{- Representação funcional do estudante: da escolha do curso à sua formação}

Dado o exposto, entendemos que os processos de aceitação e autodeclaração podem incidir sobre o percurso acadêmico do estudante e, ainda, em sua própria projeção profissional, uma vez que essese inicia desde a escolha do curso a ser frequentado, configuradapela sua representação funcional até a sua formação profissional. Conforme expõem Regiani \& Mól (2013) e Cabral (2017), a escolha do curso, por vezes, ocorre com base em conceitos segregacionistas permeados pela perspectiva da produtividade e que também tangenciam as expectativas das famílias, comunidade acadêmica e mercado de trabalho.

Evidenciando essas afirmações, a Figura 2 apresenta a distribuição desses estudantes nas três grandes áreas do conhecimento no âmbito da UFGD.

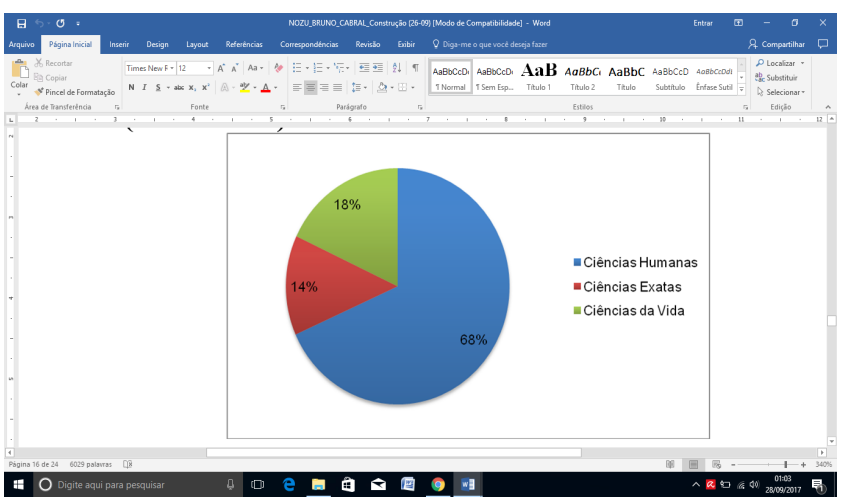

Figura 2. Distribuição de Matrículas dos Estudantes Autodeclarados como PAEE na UFGD (2012-2017) em Grandes Áreas do Conhecimento. Fonte: elaboração própria a partir de dados da PROGRAD/UFGD.

O Gráfico revela o predomínio do número de suas matrículas de alunos autodeclarados como PAEE, na UFGD, em cursos da área de Ciências Humanas, seguido por cursos das áreas de Ciências da Vida e das Ciências Exatas, respectivamente $^{7}$, cenário semelhante aos apresentados

$7 \quad \mathrm{Na}$ área de Ciências Humanas, há indicadores de matrículas nos cursos de Letras LIBRAS (41), História (12), Artes Cênicas (10), Geografia (9), Administração (8), Letras (8), Ciências Sociais (7), Psicologia (6), Relações Internacionais (6), Ciências Contábeis (5), Pedagogia (5), Ciências Econômicas (3), Educação Física (3) pelos estudos de Miranda (2009), Almeida, Bellosi e Ferreira (2015) e Ciantelli, Leite e Martins (2015).

\section{- Integralização curricular versus evasão}

Conjecturando-se às políticas institucionais e ao processo de elucidação às práticas concretas para a promoção do acesso e permanência desses alunos, importa evidenciarmos alguns índices inerentes a estudantes PAEE que concluíram suas trajetórias acadêmicas, tanto em nível de graduação quanto no de pós-graduação. Assim, no que diz respeito à integralização curricular, alguns registros de acompanhamento do LAPEI e do NuMIAc indicam que, de 2008 a 2017, 23 estudantes com deficiência concluíram cursos de graduação e pós-graduação na UFGD ${ }^{8}$ Esse número, porém, pode não representar fidedignamente o possível índice de conclusão de curso de todos os estudantes PAEE da instituição, uma vez que podem existir aqueles que optaram por não se autodeclararem.

Assim, ainda que a instituição se esforce, um desafio emergente no processo de acompanhamento desses estudantes é o de identificar tanto os estudantes PAEE que concluem seus cursos, quanto aqueles que evadem da UFGD. Isso porque, mesmo que haja uma política institucional sob a perspectiva inclusiva e ações voltadas para a promoção do acesso, permanência e sucesso acadêmico desses estudantes, ainda perduram mecanismos culturais, econômicos, logísticos, pedagógicos e atitudinais que podem culminar na sua segregação quotidiana no âmbito da instituição e, consequentemente, em sua não autodeclaração e/ou evasão (Manzini, 2008; Anache \& cols., 2014; Almeida \& cols., 2015). Nessa perspectiva, compreendemos, portanto, a existência de:

\footnotetext{
...mecanismos de inclusão e de exclusão em que as diferenças, a diversidade e o direito de igualdade são elementos da engrenagem social e contextual. Nesse sentido, discutir mecanismos para viabilizar a inclusão significa admitir a lógica intrinsecamente excludente presente nos atuais modos de organização e produção social, que remetem ao campo do "direito à diferença", sobretudo
}

e Direito (2). Por sua vez, na área de Ciências da Vida constam matrículas nos cursos de Ciências Biológicas (7), Agronomia (5), Biotecnologia (5), Nutrição (5), Medicina (4), Engenharia Agrícola (3), Gestão Ambiental (2) e Zootecnia (2). Por fim, na área de Ciências Exatas registram-se matrículas nos cursos de Engenharia de Alimentos (6), Química (6), Engenharia de Energia (4), Engenharia da Computação (2), Engenharia de Produção (2), Matemática (2), Engenharia Civil (1), Engenharia Mecânica (1) e Sistemas de Informação (1).

8 Em nível de graduação, 15 alunos surdos concluíram o curso de Letras Libras (2008-2012), um aluno surdo concluiu o curso de Engenharia de Energia (2012-2015), um aluno surdo concluiu o curso de Ciências Sociais (2013-2016), um aluno com deficiência física concluiu o curso de Ciências Biológicas (2011-2014), um aluno com deficiência física concluiu o curso de Ciências Sociais (20112014), um aluno com baixa visão concluiu o curso de Engenharia Agrícola (2009-2012), um aluno com baixa visão concluiu o curso de Economia (2009-2014). No âmbito da pós-graduação, um aluno com deficiência física concluiu o Mestrado em Educação (2011-2013) e uma aluna surda concluiu o Mestrado em Letras (2015-2017). 
quando circunstâncias impedem aos estudantes o acesso a elementos culturais, tecnológicos, científicos e humanos. Identificam-se barreiras comunicacionais, pedagógicas, atitudinais e arquitetônicas que se sobrepõem ao acesso do PAEE ao ensino superior, inclusive desfavorecendo a convivência e a transformação de atitudes e comportamentos no próprio contexto universitário. (Cabral, 2017, p. 383).

Por esse viés, é preciso conduzir o debate e o questionamento sobre a organização e as práticas essencialistas ou colonizadoras que geram a exclusão nos espaços acadêmicos.

\section{- Perspectivas futuras no âmbito das políticas institucionais da UFGD}

Diante dos desafios elencados e somando-se aos esforços implementados ao longo dos últimos dez anos, consideramos um dos eixos norteadores do PDI (2013-2017) da UFGD, que trata do "Desenvolvimento Social, Inovação e Inclusão", no qual é salientada, como projeto estruturante, a expansão de "atendimento específico a grupos historicamente desfavorecidos, em relação ao acesso, permanência, conclusão e formação de profissionais para atuação junto a estes grupos" (UFGD, 2013, p. 62). Nessa direção, o PDI lança alguns objetivos e ações, dentre os quais se destacam: desenvolver currículos e consolidar práticas pedagógicas diferenciadas, com vistas à promoção do acesso, da permanência e da equidade junto às populações do campo, indígenas e com deficiência; fortalecer a política de criação de cursos específicos e processos seletivos diferenciados; mapear demandas por acesso à educação superior junto a populações do campo, indígenas e com deficiência (UFGD, 2013).

Nesse sentido, vale ressaltar que tais prerrogativas permeavam também os objetivos do LAPEI e do NuMIAc. Especificamente, no que tange ao LAPEI (2007-2014), eram metas: a) contribuir para a construção de uma cultura de práticas inclusivas na UFGD; b) garantir a acessibilidade à informação, ao conhecimento, à permanência e a promoção da aprendizagem de todos os universitários; c) promover a eliminação de barreiras atituinais, pedagógicas, arquitetônicas e de informação e comunicação; d) realizar avaliação das necessidades específicas dos acadêmicos PAEE; e) prover formação continuada de professores, técnicos e comunidade acadêmica quanto à inclusão no ensino superior; f) apoiar ações, estudos e pesquisas voltadas ao acesso e permanência de pessoas com deficiência no ensino superior; g) promover seminários, colóquios, debates de trocas de experiências sobre a diversidade e educação inclusiva com profissionais, professores, pais e alunos com necessidades educacionais especiais (Bruno, 2009, 2011, 2012).

A partir de 2015, dado o aumento no número de estudantes PAEE que concluíam os seus respectivos cursos, o NuMIAc inclui dentre as suas metas, a de promover a relação entre o estudante PAEE e o mundo do trabalho, por meio de atividades de estágio e de formação relacionados às suas habilidades e aspirações (Cabral, 2015; UFGD, 2016).
Contudo, ainda que tais prerrogativas estejam presentes, Bruno (2011) e Ebersold e Cabral (2016) reforçam a importância de uma responsabilidade social compartilhada no processo de transformação da cultura universitária sob a perspectiva inclusiva. Nesse sentido, Cabral (2015) alerta que:

\begin{abstract}
...iniciativas pontuais não serão suficientes. É necessária uma estrutura orgânica, na qual haja uma comunicação direta entre este e as diversas instâncias da Universidade, valendo-se de cada caso específico para acionar as iniciativas de acordo com as demandas, pois para além dos objetivos do Núcleo, estas são metas de nossa instituição como um todo e, para tanto, o envolvimento das diversas instâncias e dos próprios alunos, docentes e técnicos seja motivado e preconizado em nosso contexto (p. 16).
\end{abstract}

Dado o exposto, sugerimos que, para além da política institucional, dos programas, objetivos e metas, torna-se essencial que cada Unidade Acadêmica da UFGD inclua na sua proposta de gestão, no seu projeto de curso, em seus regimentos internos e no sistema de avaliação de cursos, ações relativas ao processo de inclusão de acadêmicos com necessidades específicas, de forma que garanta não apenas o acesso, mas a promoção da aprendizagem e conclusão do curso escolhido.

\section{Considerações Finais}

Sobretudo a partir de 2007, a UFGD tem caminhado na construção de uma política de inclusão dos estudantes PAEE, enfrentando desafios e vislumbrando a garantia de condições de acesso, permanência, participação e aprendizagem destes sujeitos no ambiente universitário.

Nessa trajetória, têm sido desenvolvidas ações de apoio nos vestibulares, de planejamento e implementação das metas de acessibilidade arquitetônica e urbanística na instituição, de monitoramento das matrículas, de encaminhamento de estudantes considerados PAEE para o LAPEI e o NuMIAc avaliar, orientar e prover condições de integralização das atividades universitárias, de indicação de estratégias de adequação curricular e adaptação de recursos pedagógicos com foco na sala de aula. Além disso, atividades de ensino, pesquisa e extensão sobre inclusão educacional, envolvendo a graduação e a pós-graduação, têm sido operacionalizadas buscando avançar nas possibilidades de desenvolvimento acadêmico, pessoal e social de estudantes com necessidades educacionais específicas.

Contudo, o presente estudo trouxe à tona vários desafios, como: a) a necessidade de adequações nos processos de ingresso no Ensino Superior, considerando-se as diferenças biopsicossociais, linguísticas e culturais dos candidatos; b) a adoção de estratégias para a identificação, o acolhimento e o acompanhamento dos estudantes PAEE; c) a promoção de iniciativas relacionadas à sensibilização quanto à representação funcional do estudante, desde a escolha do curso até sua formação, com vistas a se supe- 
rar estigmatizações inerentes à sua carreira profissional e a seus potenciais; d) caminhos possíveis para garantir a integralização curricular dos estudantes PAEE, por meio de adequações curriculares e da aproximação dos docentes nos momentos de planejamento educacional. Num processo reflexivo-avaliativo, Cabral (2017, p. 384) indica que:

é chegado o momento de se transcenderem as práticas isoladas, meramente instrumentalizadas e assistencialistas, no âmbito do contexto universitário. Igualmente, é chegada a hora de se avaliarem cuidadosamente as ações executadas, que, por vezes, são centralizadas somente nas dificuldades daquele estudante que compõe o público-alvo da Educação Especial, deixando assim a oportunidade de se construírem iniciativas inclusivas universalizadas.

Nessa caminhada de uma década, urge então que a inclusão dos estudantes PAEE na UFGD seja tomada como responsabilidade compartilhada por toda a comunidade acadêmica, e não apenas como compromisso de alguns agentes e setores institucionais. Assim, é preciso avançar na consolidação de uma cultura e deuma atitude inclusiva na UFGD, que permita, coletiva e colaborativamente, desalojar barreiras estruturais, materiais, atitudinais e didático-pedagógicas que se interpõem, cotidianamente, no percurso de estudantes universitários com necessidades educacionais específicas.

\section{Referências}

Almeida, J.G.A.; Bellosi, T.C.; Ferreira, E.L. (2015). Evolução da matrícula de pessoas com deficiência na educação superior brasileira: subsídios normativos e ações institucionais para acesso e permanência. Revista Ibero-Americana de Estudos em Educação, 10, 643-660.

Anache, A.A.; Rovetto, S.S.M.; Oliveira, R.A. (2014). Desafios da implantação do atendimento educacional especializado no ensino superior. Revista Educação Especial, 27 (49), 299-312.

Bruno, M.M.G. (2009). Proposta de consolidação do Laboratório de Acessibilidade e Práticas de Educação Inclusiva: democratizando o acesso, promovendo cidadania. Dourados: LAPEI/UFGD. (Formulário de Projeto de Extensão).

Bruno, M.M.G. (2011). Políticas afirmativas para a inclusão do surdo no ensino superior: algumas reflexões sobre o acesso, a permanência e a cultura universitária. Revista Brasileira de Estudos Pedagógicos, 92 (232), 542-556.

Bruno, M.M.G. (2012). Relatório de atividades Programa Incluir. Dourados: LAPEI/UFGD. (Relatório interno).

Cabral, L.S.A. (2015). Diretrizes preliminares para a implementação do Núcleo Multidisciplinar para a Inclusão e Acessibilidade da UFGD. Dourados: UFGD.
Cabral, L.S.A. (2017). Inclusão do público-alvo da educação especial no ensino superior brasileiro: histórico, políticas e práticas. Revista de Educação PUC-Campinas, 22(3), 371-388.

Cabral, L.S.A.; Mendes, E.G.; De Anna, L.; Ebersold, S. (2015). Academic and Professional Guidance for Tertiary Students with Disabilities: Gathering Best Practices throughout European Universities. Open Journal of Social Sciences, 03, 48-59.

Ciantelli, A.P.C.; Leite, L.P.; Martins, S.E.S.O. (2015). Inclusão no ensino superior: mapeamento e análise de matrículas de alunos com deficiência e/ou mobilidade reduzida na UNESP. In: Mendes, E. G.; Almeida, M. A. (Orgs.), Educação especial inclusiva: legados históricos e perspectivas futuras (pp. 287-302). São Carlos: Marquezine \& Manzini; ABPEE.

Cury, C.R.J.; Horta, J.S.B.; Fávero, O. (1996). A Relação EducaçãoSociedade-Estado pela mediação jurídico-constitucional. In: Fávero, O.(Org.),A educação nas Constituintes Brasileiras: 18231988(pp. 5-30). Campinas: Autores Associados.

Ebersold, S.; Cabral, L.S.A. (2016). Enseignement supérieur, orchestration de l'accessibilité et strategies d'accompagnement. Education et Francophonie, 44 (1), 132-153.

Gil, A.C. (2009). Como elaborar projetos de pesquisa. São Paulo: Atlas.

Hova, G.L.S. (2010). A política de acessibilidade na cidade de Dourados/MS: um estudo sobre as práticas discursivas e não discursivas. Dissertação de Mestrado, Universidade Federal da Grande Dourados, Dourados-MS.

Manzini, E.J. (2008). Acessibilidade: um aporte na legislação para o aprofundamento do tema na área de educação. In: Baptista, C. R.; Caiado, K.R.M.; Jesus, D.M. (Orgs.), Educação especial:diálogo e pluralidade (pp. 281-289). Porto Alegre: Mediação.

Miranda, T.G. (2009). A inclusão de pessoas com deficiência na universidade. In: Jesus, D.M.; Baptista, C.R.; Barreto, M.A.S.C.; Victor, S.L. (Orgs.), Inclusão, práticas pedagógicas e trajetórias de pesquisa (pp. 120-131). Porto Alegre: Mediação.

Moreira, L.C.; Bolsanello, M.A.; Seger, R.G. (2011). Ingresso e permanência na Universidade: alunos com deficiências em foco. Educar em Revista, 41, 125-143.

Nantes, J.M. (2012). O intérprete de língua de sinais sob o olhar do aluno surdo no ensino superior: uma análise do discurso na perspectiva foucaultiana. Dissertação de Mestrado, Universidade Federal da Grande Dourados, Dourados-MS.

Nascimento, G.V.S. (2013). Educação, inclusão e tecnologias da Informação e Comunicação: o uso de tecnologias da informação e comunicação como recurso para inclusão de deficientes auditivos em Dourados/MS. Dissertação de Mestrado, Universidade Federal da Grande Dourados, Dourados-MS. 
Nascimento, R.A.L. (2015). O impacto dos recursos de tecnologia assistiva na educação e inclusão de pessoas com deficiência visual. Dissertação de Mestrado, Universidade Federal da Grande Dourados, Dourados-MS.

Peixoto, M.C.L. (2001). O Acesso ao Ensino Superior nos periódicos nacionais. In: Sguissardi, V.; Silva Júnior, J.R. (Orgs.),Educação Superior:análises e perspectivas de pesquisa (pp.107-130). São Paulo: Xamã.

Regiani, A.M.; Mól, G. S. (2013). Inclusão de uma aluna cega em um curso de licenciatura em química. Ciência \& Educação, 19 (1), 123-134.

Santos, B.S. (1997). Da ideia de universidade à universidade de ideias. In: Santos, B. S. (Org.), Pela mão de Alice: o social e o político na pós-modernidade(pp.187-226). São Paulo: Cortez.

Santos, B.S. (2005). A Universidade no século XXI: para uma reforma democrática e emancipatória da Universidade. São Paulo: Cortez.
Thacher, D. (2006). The Normative Case Study. American Journal of Sociology, 111 (6), 1631-1676.

Unesco. (1998). World Conference on Higher Education in the Twenty-first Century: vision and action. Paris: Unesco.

Universidade Federal da Grande Dourados [UFGD] (2013). Plano de Desenvolvimento Institucional - PDI (2013-2017). Dourados: UFGD.

Universidade Federal da Grande Dourados [UFGD] (2016). Regimento do Núcleo Multidisciplinar para a Inclusão e Acessibilidade da Universidade Federal da Grande Dourados - NuMIAc/UFGD. Dourados: UFGD.

Yin, R. K. (2005). Estudo de caso: planejamento e métodos. Porto Alegre: Bookman.

License information: This is an open-access article distributed under the terms of the Creative Commons Attribution License (type CCBY), which permits unrestricted use,distribution and reproduction in any medium, provided the original article is properly cited.

\section{Sobre os autores}

Washington Cesar Shoiti Nozu (wcsn1984@yahoo.com.br)

Professor Adjunto, Universidade Federal da Grande Dourados (UFGD). Docente do Programa de Pós-Graduação em Fronteiras e Direitos Humanos. Doutor e Mestre em Educação pela Universidade Federal da Grande Dourados (UFGD). Licenciado em Pedagogia e Bacharel em Direito pela Universidade Estadual de Mato Grosso do Sul (UEMS). Desenvolve estudos e pesquisas em Educação e em Direitos Humanos. https://orcid.org/0000-0003-1942-0390

Marilda Moraes Garcia Bruno (marildabruno@ufgd.edu.br)

Professora Associada, aposentada na Universidade Federal da Grande Dourados (UFGD). Docente do Programa de Pós-Graduação em Educação da Faculdade de Educação. Pesquisadora da Linha Educação e Diversidade. Pedagoga com Habilitação em Educação Especial (Ensino do deficiente Visual) pela Universidade de São Paulo USP, Graduação em Letras pela Universidade do Sagrado Coração. Mestrado no Programa de Mestrado em Educação da Universidade Católica Dom Bosco e Doutorado em Ensino da Educação Brasileira pela Universidade Estadual Paulista - Júlio de Mesquita Filho.

https://orcid.org/0000-0002-1568-2185

Leonardo Santos Amâncio Cabral (prof.leonardocabral@gmail.com)

Professor Adjunto II (Educação Especial) vinculado ao Departamento de Psicologia da Universidade Federal de São Carlos-UFSCar. Docente do Programa de Pós-Graduação em Educação Especial. Possui Mestrado, Doutorado e Pós-Doutorado em Educação Especial pela Universidade Federal de São Carlos-UFSCar. Doutorado Pleno em 'Culturas, deficiência e inclusão: educação e formação', pela Universidade de Roma 'Foro Italico' (título adjunto de 'Doctor Europeaus' emitido pela Comissão Européia). Licenciatura Plena em Educação Física pela Universidade Federal de Uberlândia. https://orcid.org/0000-0003-3520-3687 